\title{
Effect of adsorbents in diets on production efficiency of broiler with high nutritional and ecological characteristics
}

\author{
R.B. Temiraev ${ }^{1 \& 2}$, S.F. Sukhanova ${ }^{3}$, T.T. Tarchokov ${ }^{4}$, D. V. Osepchuk ${ }^{5 \& 6}$, Z.T. \\ Baeva $^{1}$, Z.A. Kubatieva ${ }^{2}$, M. K. Kozhokov ${ }^{4}$, Z.Yu. Kaloeeva ${ }^{7}$, A.V. \\ Khmelevskaya $^{7}$
}

\begin{abstract}
${ }^{1}$ North-Caucasian Mining and Metallurgical Institute (State Technological University), Vladikavkaz 362021; ${ }^{2}$ Gorsky State Agrarian University, 362040, Vladikavkaz, 37 Kirov Street; ${ }^{3}$ Kurgan state agricultural academy after T.S. Maltsev, Kurgan 641300; ${ }^{4}$ Kabardino-Balkarian State Agrarian University named after Kokov, Nalchik, 360030; ${ }^{5}$ Krasnodar Research Centre for Animal Husbandry and Veterinary Medicine, Krasnodar 350055; ${ }^{6}$ Kuban State Agrarian University named after I.T. Trubilina, Krasnodar 350044; ${ }^{7}$ North-Ossetian State University named after K.L. Khetagurov, Vladikavkaz, 362025, Russian Federation.
\end{abstract}

Journal of Livestock Science (ISSN online 2277-6214) 11: 26-32

Received on 1/11/2019; Accepted on 15/1/2020

doi. 10.33259/JLivestSci.2020.26-32

\section{Abstract}

Metallurgical enterprises are the main source of environmental pollution with heavy metals. Toxicants pose a serious threat to the consumer's health, so scientific research on diminishing their adverse effect on sanitaryhygienic properties of poultry meat is of high importance when organizing effective environmental management and ensuring food security. The purpose of the study is to devise a method for reducing a negative impact of heavy metals on productivity and sanitary-hygienic properties of meat by admixing adsorbents to a formulation of animal feeds. To analyse the concentration of heavy metals, the atomic adsorption method was applied. Experimental data were statistically processed using SNEDECOR application package. In the industrial territory of RNO - Alania, the prudent use of the adsorbents such as citrus pectin in the amount of $200 \mathrm{~g} / \mathrm{ton}$ and Toxiban Max in the amount of $1000 \mathrm{~g} /$ ton admixed to barley-corn-soybean based feeds of local production allows achieving the maximum effect. Due to the synergistic effect of the tested drugs, there was an increase in the number of red blood cells, haemoglobin and bactericidal and lysozyme activities in the blood of the experimental birds; at the same time, the concentration of zinc lowered 1.98 times, lead -2.71 times and cadmium - 2.03 times. The broiler chickens of the 4-experimental group were different from the 1-control analogues in weight parameters, slaughter yield and protein qualitative index which increased by $12.9 \%, 0.74 \%$ and $17.8 \%$ respectively. Zinc concentration in the examined muscle samples was 3.48 times lower than in the 1-control group, lead concentration -3.11 times and cadmium concentration -3.54 times.

Keywords: Broiler; Heavy metals; Adsorbents in the diet; Sanitary-hygienic properties of meat; Environmental Security; Republic of North Ossetia - Alania (RNO - Alania) 


\section{Introduction}

At the current stage of society development anthropogenic impact is observed in virtually all ecosystems. Consequently, improving the environmental security concept that is aimed at preventing a potential damage to human health caused by intensive environmental pollution with chemical toxicants is the first priority of the government policy on decreasing the negative effect of anthropogenic factors on the environment (Baeva et al., 2013; Fyodorov and Kuzmin, 2013).

The compounds of heavy metals can be differentiated from other chemical pollutants due to their high degree of toxicity even in trace amounts and represent a special threat to the ecosystem. They exhibit high migration properties and get accumulated in soils, plants and animal products, what makes them extremely dangerous to human health even when presented in very low concentrations. Toxic effect of heavy metals is explained by the fact that in human and animal bodies they bind with proteins and form insoluble compounds that alter properties and inactivate several vital enzymes involved in anabolic and catabolic reactions (Daukaev and Suleymanov 2009; Kokaeva, 2008).

This problem is particularly acute for industrialized regions that suffer from anthropogenic as well as natural negative effects of heavy metals on sanitary-hygienic properties of animal products and consumers' health. In Russia, the Republic of North Ossetia - Alania (RNO - Alania) is one of the regions with high concentration of mining and processing enterprises. Large non-ferrous metal processing plants, road transport and agriculture are the major sources of anthropogenic environmental pollution with heavy metals (Temiraev et al., 2012; Tletseruk et al., 2013).

In the territory of RNO - Alania, the given factors create a considerable danger to sanitary-hygienic qualities of poultry meat, since the majority of poultry-producing companies of the region are located in the suburban area which is characterized by a high content of heavy metals in soil and forage crops. At that, the main feed ingredients include grain crops, such as barley and corn, and soybean which are grown locally to reduce production cost of poultry products. However, there emerges a risk of a decrease in environmental security of these products (Baeva et al., 2014). Working towards the optimal solution to this problem is a principal task for modern scientists (Kuzmin, 2015; Kuzmin, 2016).

In this regard, it is of critical importance to undertake scientific research on lessening the negative impact of heavy metals on productivity and sanitary-hygienic characteristics of poultry meat through the use of adaptive selection of feed adsorbents when organizing effective environmental management and ensuring food security of the region. The study aims to develop a method for diminishing the adverse effect of heavy metals on productivity, sanitary-hygienic properties of meat and blood parameters of broiler chickens through the prudent use of adsorbents admixed to barley-corn-soybean based feeds.

The purpose of the present study is to devise a method for reducing a negative impact of heavy metals on productivity and sanitary-hygienic properties of meat by admixing adsorbents to a formulation of animal feeds.

\section{Material and methods}

To accomplish the stated objective, the scientific and economic experiment with broiler chickens of Cobb500 cross was conducted at the poultry farm 'Vladikavkazskaya' (RNO - Alania, Longitude: 44 40'04 " East, Latitude: $43^{\circ} 02^{\prime} 12^{\prime \prime}$ North. Altitude: $671 \mathrm{~m}$ ). One-day old broiler chickens were divided into 4 groups each of 100 chicks using the analogue-group method (with account for body weight, origin and overall health). In both experiments, the rearing period of chickens was 42 days.

Feeding of the experiment birds was carried out according to the scheme shown in Table 1 . The basic diet (BD) of chickens of the compared groups included standard barley-corn-soybean based feeds of local production with elevated concentration levels of heavy metals.

During the trials, the diet of the experimental meat-type poultry was organized in two stages and differentiated (Lopatov, 1999) according to feed formulation and broiler chicks age (Table 2): 1) PK-5 formula (128-day old) and 2) PK-6 formula (29-42-day old).

Table 1. Scheme of the scientific and economic experiment $\quad(n=100)$

\begin{tabular}{|l|l|l|l|}
\hline Group & \multirow{2}{*}{$\begin{array}{l}\text { Basis diet } \\
\text { (BD) }\end{array}$} & \multicolumn{2}{|l|}{ Doses of supplementation, g / t feed } \\
\cline { 3 - 4 } & & Citrus pectin & Toxiban Max \\
\hline 1-Control & BD & - & - \\
\hline 2-Experimental & BD & 200 & - \\
\hline 3-Experimental & BD & - & 1000 \\
\hline 4-Experimental & BD & 200 & 1000 \\
\hline
\end{tabular}


Table 2 - Composition and nutrition of feed for broiler chickens

\begin{tabular}{|c|c|c|}
\hline \multirow[t]{2}{*}{ Components, $\%$} & \multicolumn{2}{|c|}{ Recipe } \\
\hline & feed PK-5 & feed PK-6 \\
\hline Barley & 40 & 42.5 \\
\hline Corn & 20.5 & 25.0 \\
\hline Soybean & 15.5 & 15.0 \\
\hline Wheat bran & 3 & 5.0 \\
\hline Herbal flour & 2.0 & 2.0 \\
\hline Hydrolysis yeast & 6.0 & 3.4 \\
\hline Fish flour & 5.2 & 2.0 \\
\hline Feed fat & 1.0 & 1.0 \\
\hline Chalk feed & 2.0 & 1.0 \\
\hline Reverse dry & 2.5 & 0.2 \\
\hline Common salt & 0.3 & 1.0 \\
\hline Tricalcium phosphate & 2.0 & 0.9 \\
\hline Premix P6-1-89 & 1.0 & 1.0 \\
\hline \multicolumn{3}{|c|}{$100 \mathrm{~g}$ of feed contained: } \\
\hline exchange energy, MJ & 1297 & 1339 \\
\hline crude protein, $\mathrm{g}$ & 23.0 & 21.01 \\
\hline crude fat, $\mathrm{g}$ & 6.87 & 6.48 \\
\hline crude fiber, $\mathrm{g}$ & 4,02 & 4.03 \\
\hline calcium, $\mathrm{g}$ & 1.05 & 1.21 \\
\hline phosphorus, $\mathrm{g}$ & 0.41 & 0.71 \\
\hline sodium, $\mathrm{g}$ & 0.21 & 0.20 \\
\hline lysine, $\mathrm{g}$ & 1.27 & 0.84 \\
\hline methionine + cystine, $\mathrm{g}$ & 0.93 & 0.64 \\
\hline linoleic acid, $g$ & 1.11 & 1.2 \\
\hline $\begin{array}{l}\text { For } 1 \mathrm{t} \text { of feed is added: } \\
\text { Methionine, } \mathrm{g}\end{array}$ & 600 & 700 \\
\hline
\end{tabular}

The adsorbents used were introduced into the compounding of feeds with the help of industrial dispensers by uniform mixing.

Citrus pectin is an odorless powder of light brown or cream color. This type of pectin is widely used in food and processing, pharmaceutical industries, as well as in agriculture due to the fact that it serves as an adsorbent, gelling agent, water-retaining agent, stabilizer and thickener. In animal husbandry and poultry farming it is used as a feed additive with adsorption properties, that is, it binds in the gastrointestinal tract and removes various toxins from the body (mycotoxins, heavy and radioactive metals, nitrates and nitrites, etc.). The producer of citrus pectin is NutriMax (Moscow, Russia). Another adsorbent used was Toxiban Max (produced by Novus Europe, Belgium) containing aluminosilicates, yeast culture, gelling agent and marigold extract.

Morphological and biochemical blood parameters were examined in 5 chickens from each group using conventional practices. Five 42-day old broilers from each group were slaughtered with their body weight taken into account. The concentration of heavy metals in the samples of feedstuffs, blood and meat was analysed using a spectrophotometer AAZ-115-M1 in the laboratory of agroecology of the Gorsky State Agrarian University, Russian Federation).

The collected experimental material was subjected to Student's $t$-test analyses on a personal computer using SNEDECOR application package.

\section{Results and discussion}

The main feed ingredients such as grains of barley, corn and soybean for the experimental birds were purchased from local producers. Based on the above, we determined the concentration of zinc, lead and cadmium in the composition of animal feeds PK-5 and PK-6 based on barley, corn and soybean (Table 3). It was found that the formulation of the animal feeds PK-5 and PK-6 used for the experimental groups of birds contained elevated concentrations of zinc by 30.4 and $28.7 \%$, lead - by 19.6 and $18.8 \%$, and cadmium - by 25.0 and $20.0 \%$ respectively. It was found that the formulation of the animal feeds PK-5 and PK-6 used for the experimental groups of birds contained elevated concentrations of zinc by 30.4 and $28.7 \%$, lead - by 19.6 and $18.8 \%$, and cadmium - by 25.0 and $20.0 \%$ respectively. 
Temiraev et al. 2020/ J. Livestock Sci. 11: 26-32

Table 3 - Concentration of heavy metals in animal feeds used for broiler chickens (experiment 2)

\begin{tabular}{|l|l|l|l|}
\hline \multirow{2}{*}{\multicolumn{1}{|c|}{ Compounding }} & \multicolumn{3}{c|}{ Concentration, mg/kg } \\
\cline { 2 - 4 } & Zinc & Lead & Cadmium \\
\hline Maximum allowable conc (MAC) & 100.0 & 5.0 & 0.4 \\
\hline PK-5 (1-28-day old chicks) & 130.4 & 5.98 & 0.50 \\
\hline As \% of MAC & 130.4 & 119.6 & 125.0 \\
\hline PK-6 (29-42-day old chicks) & 128.7 & 5.94 & 0.48 \\
\hline As \% of MAC & 128.7 & 118.8 & 120.0 \\
\hline
\end{tabular}

Table 4 - Morphological blood composition of the broiler chickens $\quad(n=5)$

\begin{tabular}{|l|l|l|l|l|}
\hline \multirow{2}{*}{\multicolumn{1}{c|}{ Indicator }} & \multicolumn{4}{|c|}{ Group } \\
\cline { 2 - 5 } & 1 -Control & 2-Experiment & 3-Experiment & 4-Experiment \\
\hline Erythrocyte count,1012/L & $3.44 \pm 0.20$ & $3.73 \pm 0.31$ & $3.80 \pm 0.28$ & $3.96 \pm 0.25$ \\
\hline Leukocyte count, 109/L & $8.88 \pm 0.31$ & $8.75 \pm 0.34$ & $8.84 \pm 0.40$ & $8.96 \pm 0.46$ \\
\hline Haemoglobin, g/L & $78.4 \pm 0.35$ & $81.7 \pm 0.41$ & $82.0 \pm 0.37$ & $84.5 \pm 0.45$ \\
\hline
\end{tabular}

Table 5 - Blood serum biochemical parameters of the broiler chickens $\quad(n=5$

\begin{tabular}{|l|l|l|l|l|}
\hline \multirow{2}{*}{ Indicator } & \multicolumn{4}{|c|}{ Group } \\
\cline { 2 - 5 } & 1 -Control & 2-Experiment & 3 -Experiment & 4 -Experiment \\
\hline Total protein, g/L & $63.7 \pm 2.6$ & $66.9 \pm 3.2$ & $67.3 \pm 3.0$ & $68.8 \pm 2.9$ \\
\hline Glucose, $\mathrm{mmol} / \mathrm{L}$ & $44.55 \pm 0.31$ & $47.56 \pm 0.36$ & $47.70 \pm 0.26$ & $49.88 \pm 0.37$ \\
\hline Cholesterol, mmol/L & $2.96 \pm 0.003$ & $2.56 \pm 0.004$ & $2.51 \pm 0.005$ & $2.10 \pm 0.004$ \\
\hline Calcium, mmol/L & $12.78 \pm 0.32$ & $13.67 \pm 0.28$ & $13.79 \pm 0.40$ & $14.22 \pm 0.31$ \\
\hline Phosphorus, mmol/L & $5.24 \pm 0.16$ & $5.67 \pm 0.12$ & $5.73 \pm 0.17$ & $5.80 \pm 0.19$ \\
\hline Lysozyme activity, \% & $17.28 \pm 0.24$ & $19.65 \pm 0.30$ & $19.89 \pm 0.22$ & $21.39 \pm 0.28$ \\
\hline Bactericidal activity, \% & $39.00 \pm 0.36$ & $48.02 \pm 0.32$ & $48.47 \pm 0.44$ & $51.89 \pm 0.40$ \\
\hline Zinc, $\mathrm{mg} / \mathrm{kg}$ & $25.44 \pm 0.25$ & $18.06 \pm 0.28$ & $17.78 \pm 0.30$ & $12.87 \pm 0.22$ \\
\hline Lead, $\mathrm{mg} / \mathrm{kg}$ & $1.60 \pm 0.03$ & $0.81 \pm 0.05$ & $0.77 \pm 0.04$ & $0.59 \pm 0.03$ \\
\hline Cadmium, $\mathrm{mg} / \mathrm{kg}$ & $0.065 \pm 0.003$ & $0.049 \pm 0.005$ & $0.046 \pm 0.006$ & $0.032 \pm 0.004$ \\
\hline
\end{tabular}

Table 6 - Slaughter parameters of the compared groups of broilers $(n=5)$

\begin{tabular}{|l|l|l|l|l|}
\hline \multirow{2}{*}{\multicolumn{1}{|c|}{ Indicator }} & \multicolumn{4}{c|}{ Group } \\
\cline { 2 - 5 } & 1 -Control & 2 -Experiment & 3-Experiment & 4-Experiment \\
\hline Pre-slaughter weight of one bird, g & $2140.1 \pm 5.5$ & $2273.0 \pm 5.6$ & $2288.9 \pm 5.9$ & $2389.3 \pm 5.1$ \\
\hline Wt of a semi-eviscerated carcass, $\mathrm{g}$ & $1787.6 \pm 4.5$ & $1888.5 \pm 5.1$ & $1910.3 \pm 5.5$ & $1995.3 \pm 5.1$ \\
\hline In \% to live weight & 83.53 & 83.07 & 83.45 & 83.51 \\
\hline Wt of an eviscerated carcass, $\mathrm{g}$ & $1390.6 \pm 4.3$ & $1484.7 \pm 3.6$ & $1499.0 \pm 4.1$ & $1570.2 \pm 4.4$ \\
\hline Slaughter yield, \% & 64.98 & 65.32 & 65.48 & 65.72 \\
\hline Weight of edible parts, $\mathrm{g}$ & 1104.3 & 1187.9 & 1200.5 & 1273.0 \\
\hline Weight of inedible parts, $\mathrm{g}$ & 683.3 & 700.6 & 709.8 & 722.3 \\
\hline Ratio of edible to inedible parts & 1.61 & 1.69 & 1.69 & 1.76 \\
\hline Carcasses (\%): 1 st category & 72 & 78 & 81 & 85 \\
\hline 2nd category & 28 & 22 & 19 & 15 \\
\hline
\end{tabular}

Table 7 - Chemical composition of thigh muscles of broiler chickens, \% (n=5

\begin{tabular}{|l|l|l|l|l|}
\hline \multirow{2}{*}{ Indicator } & \multicolumn{4}{c|}{ Group } \\
\cline { 2 - 6 } & 1 -Control & 2-Experiment & 3-Experiment & 4-Experiment \\
\hline Dry matter & $23.54 \pm 0.17$ & $24.02 \pm 0.21$ & $24.15 \pm 0.12$ & $24.68 \pm 0.23$ \\
\hline Protein content & $19.20 \pm 0.14$ & $19.83 \pm 0.20$ & $19.90 \pm 0.10$ & $20.33 \pm 0.19$ \\
\hline Fat content & $3.28 \pm 0.04$ & $3.02 \pm 0.06$ & $2.97 \pm 0.05$ & $2.91 \pm 0.03$ \\
\hline Zinc $($ MAC $=70 \mathrm{mg} / \mathrm{kg})$ & $94.23 \pm 0.23$ & $71.03 \pm 0.21$ & $67.74 \pm 0.32$ & $31.44 \pm 0.25$ \\
\hline Cadmium $(\mathrm{MAC}=0.05 \mathrm{mg} / \mathrm{kg})$ & $0.083 \pm 0.002$ & $0.054 \pm 0.004$ & $0.048 \pm 0.003$ & $0.029 \pm 0.005$ \\
\hline Lead $(\mathrm{MAC}=0.5 \mathrm{mg} / \mathrm{kg})$ & $0.87 \pm 0.02$ & $0.56 \pm 0.03$ & $0.52 \pm 0.05$ & $0.34 \pm 0.03$ \\
\hline
\end{tabular}


In order to intensify metabolism, increase meat productivity and improve sanitary-hygienic properties of broiler meat, it is required to reduce the detrimental effect of heavy metals. For this reason, we explored the influence of the feed additives such as citrus pectin and Toxiban Max, used in the diets of the experiment chickens to detoxify the given toxicants, on morphological blood composition (Table 4).

During the experiment, it was found that supplementation of feed additives with adsorption qualities (citrus pectin and Toxiban Max), individually or in combination, to diets for excreting heavy metals, did not exert a marked influence on morphological parameters in broilers blood which remained within the physiological range. Due to the synergistic effect of the tested drugs, if taken together, there was a significant increase $(\mathrm{P}<0.05)$ in the erythrocyte count by $0.52 \times 10^{12} / \mathrm{L}$ and the haemoglobin level - by $6.1 \mathrm{~g} / \mathrm{L}$ in the 4 -experimental group compared to the control analogues.

At the same time, the difference in the leukocyte count in broilers' blood was not considered significant $(\mathrm{P}>0.05)$, since in all cases the difference in this parameter in the birds of the compared groups was within the error in the arithmetic mean. This suggests that the use of the feed additives (citrus pectin and Toxiban Max) in the composition of animal feeds with elevated concentrations of zinc, lead and cadmium exerted a stimulating effect on the hematopoiesis in broilers.

During the experiment, we studied the effect of the tested adsorbent drugs on some biochemical blood parameters, including the accumulation level of the given toxicants (Table 5). The adsorbents added in combination to barley-corn-soybean based diets with elevated concentrations of zinc, lead and cadmium positively influenced the protein metabolism in the broiler chicks. Due to the synergistic effect of the tested drugs, in the process of heavy metal detoxification there was a significant $(\mathrm{P}<0.05)$ increase in total protein by $5.1 \mathrm{~g} / \mathrm{L}$ in the serum of the 4 experimental birds compared to the control chickens.

Moreover, according to hematologic examination, the bactericidal and lysozyme activities in the blood serum of the 4-experimental group intensified significantly $(\mathrm{P}<0.05)$ - by $12.89 \%$ and $4.11 \%$ respectively, as compared to the control group of broilers. The findings suggest that the adsorbent drugs (citrus pectin and Toxiban Max), taken in combination, positively influence innate immunity parameters of the broilers of the 4-experimental group due to the better removal of metallic toxic substances from the body.

Metabolites of carbohydrate metabolism are formed when amylolytic and cellulolytic enzymes cleave polysaccharides contained in animal feeds in gastrointestinal tract. After the absorption into the bloodstream through the wall of the small intestine, the body of birds uses these metabolites mostly as fuel to produce energy. The other part of carbohydrate metabolites is involved in lipid metabolism with simultaneous cholesterol accumulation in blood. For this reason, the combined use of the tested adsorbents in the 4-experimental group resulted in a significant $(\mathrm{P}<0.05)$ increase in serum glucose by $5.33 \mathrm{mmol} / \mathrm{L}$ and a simultaneous fall in cholesterol by 0.86 $\mathrm{mmol} / \mathrm{L}(\mathrm{P}<0.05)$ when compared to the broiler chickens of the 1-control group. This indicates the optimization of carbohydrate and lipid metabolism in the birds of the 4-experimental group when removing heavy metals by supplementing animal feeds with citrus pectin and Toxiban Max.

It was found that the combined intake of these adsorbents added to barley-corn-soybean based diets with the elevated levels of zinc, lead and cadmium stimulated mineral metabolism in the blood serum of the broilers in the 4experimental group. Hence, the concentration of calcium and inorganic phosphorus in the blood serum of the birds of this group was significantly $(\mathrm{P}<0.05)$ higher than in the control chickens - by $1.44 \mathrm{mmol} / \mathrm{L}$ and $0.56 \mathrm{mmol} / \mathrm{L}$ respectively.

The combined use of $200 \mathrm{~g}$ of citrus pectin and $1000 \mathrm{~g}$ of Toxiban Max admixed with each ton of animal feeds produced the most prominent detox effect in the birds of the 4-experimental group which led to a significant $(\mathrm{P}<0.05)$ decrease in concentration of zinc (1.98 times), lead (2.71 times) and cadmium (2.03 times), if compared to the control analogues. In our opinion, the reason behind this is the increased secretion of exogenous enzymes due to the binding of these toxic elements with citrus pectin's D-galacturonic acid which forms strong complexes with them. In addition, Toxiban Max owing to aluminosilicates in its composition promoted adsorption of heavy metals in the alimentary canal.

Russian customers should be provided with a diet containing low-fat chicken meat with high consumer and sanitary-hygienic properties. However, it is hard to comply with this requirement in the territory of RNO - Alania, since the suburban area of the city of Vladikavkaz is classified as a zone with serious anthropogenic contamination of soil and forage crops with heavy metals.

At the end of the experiment, the control slaughter of 5 broilers from each group was carried out. This allowed determining the effect exerted by the tested drugs on slaughter parameters in the process of detoxification of zinc, lead and cadmium (Table 6).

The study indicated that due to the joint supplementation of adsorbent drugs (citrus pectin and Toxiban Max) to animal feeds with excessive levels of heavy metals, the birds of the 4-experimental group displayed the best slaughter parameters. At that, semi-eviscerated carcass weight and eviscerated carcass weight in this group appeared significantly $(\mathrm{P}<0.05)$ bigger compared to the control chickens - by $11.6 \%$ and $12.9 \%$ respectively; the slaughter yield also increased by $0.74 \%$.

Because of detoxifying properties of $200 \mathrm{~g} / \mathrm{ton}$ of citrus pectin and $1000 \mathrm{~g} / \mathrm{ton}$ of Toxiban Max, the destructive effect of heavy metals on formation of muscular tissue of the broiler chickens diminished, and this resulted in the improvement of morphological characteristics of carcasses of the experimental chickens. For 
example, due to the combined use of citrus pectin and Toxiban Max, the broiler chicks of the 4-experimental group demonstrated an increase in the weight of edible parts by $15.3 \%$, the ratio of edible to inedible parts increased by $9.3 \%$ and the yield of the $1^{\text {st }}$ category carcasses rose by $13 \%$ in comparison with the 1 -control group.

While conducting the experiment, considerable attention was paid to the influence that the tested adsorbents, used for elimination of excess amounts of zinc, lead and cadmium, exert on consumer properties of the experimental chicken meat. Given that thigh muscles tend to accumulate more metallic toxic substances than other parts of the body, we examined chemical composition of these muscles (Table 7).

In the course of the studies, it was found that meat of the 4-experimental group of chickens was characterized by the best chemical composition owing to the combined supplementation of citrus pectin and Toxiban Max to the formulation of animal feeds with elevated concentration of heavy metals. In comparison to the 1-control analogues, the test samples of thigh muscles of the 4-experimental birds displayed a significant $(\mathrm{P}<0.05)$ increase in the level of dry matter by $1.14 \%$ and protein content - by $1.13 \%$ with a simultaneous decrease in fat content - by $0.37 \%$ $(\mathrm{P}<0.05)$; amounts of zinc were 3 times lower, lead -2.56 times and cadmium -2.86 times. It worth noting that the content of all three toxic metals in meat of the 4-experimental group was below the maximum allowable concentration.

Considering the fact that, from a technological point of view, the most valuable part is white meat, we studied chemical composition of breast muscle samples of the experimental chickens (Table 8).

Table 8 - Chemical composition of breast muscle (\%) and biological full-value of meat of the experimental chickens $(\mathrm{n}=5)$

\begin{tabular}{|l|l|l|l|l|}
\hline \multirow{2}{*}{\multicolumn{1}{c|}{ Indicator }} & \multicolumn{3}{c|}{ Group } \\
\cline { 2 - 5 } & 1 -Control & 2-Experiment & 3-Experiment & 4-Experiment \\
\hline Dry matter & $25.43 \pm 0.16$ & $26.24 \pm 0.20$ & $26.45 \pm 0.17$ & $26.76 \pm 0.15$ \\
\hline Fat content & $2.38 \pm 0.02$ & $2.21 \pm 0.05$ & $217 \pm 0.06$ & $2.24 \pm 0.07$ \\
\hline Protein content & $21.91 \pm 0.12$ & $22.63 \pm 0.11$ & $22.82 \pm 0.16$ & $23.00 \pm 0.13$ \\
\hline Tryptophan, \% & $1.60 \pm 0.004$ & $1.68 \pm 0.005$ & $1.70 \pm 0.003$ & $1.74 \pm 0.004$ \\
\hline Oxyproline, \% & $0.37 \pm 0.002$ & $0.38 \pm 0.003$ & $0.37+0.004$ & $0.36 \pm 0.002$ \\
\hline PQI & $4.10 \pm 0.05$ & $4.42 \pm 0.10$ & $4.59 \pm 0.09$ & $4.83 \pm 0.11$ \\
\hline Zinc $(\mathrm{MAC}=70 \mathrm{mg} / \mathrm{kg})$ & $89.04 \pm 0.28$ & $65.43 \pm 0.24$ & $63.77 \pm 0.20$ & $25.57 \pm 0.30$ \\
\hline Cadmium $(\mathrm{MAC}=0.05 \mathrm{mg} / \mathrm{kg})$ & $0.078 \pm 0.003$ & $0.047 \pm 0.002$ & $0.044 \pm 0.004$ & $0.022 \pm 0.003$ \\
\hline Lead $(\mathrm{MAC}=0.5 \mathrm{mg} / \mathrm{kg})$ & $0.81 \pm 0.01$ & $0.50 \pm 0.04$ & $0.48 \pm 0.04$ & $0.26 \pm 0.02$ \\
\hline
\end{tabular}

The adsorbent drugs (citrus pectin and Toxiban Max) produced a synergistic effect which facilitated the removal of heavy metals from the chickens' body. Due to that, the samples of breast muscle taken from the 4experimental group contained significantly $(\mathrm{P}<0.05)$ more dry matter by $1.33 \%$ and protein - by $1.09 \%$ when compared to the 1-control group.

This suggests that during heavy metal detoxification triggered by the combined supplementation of the two adsorbents (citrus pectin and Toxiban Max) to barley-corn-soybean based diets, the synthesis of proteinases in the meat-type broilers was optimized. Proteinases not only increase the protein content in muscle tissue, but also improve biological full-value of proteins. Due to adsorption of the toxicants by the tested adsorbent drugs in the gastrointestinal tract of the 4-experimental chicks, there was a significant $(\mathrm{P}<0.05)$ increase in the tryptophan content of broiler breast muscle samples by $0.14 \%$ in relation to the 1 -control analogues, what caused a rise in protein qualitative index (PQI; the tryptophan/oxyproline ratio) by $17.8 \%$.

Along with protein qualitative index, we paid special attention to the sanitary-hygienic properties of meat of broilers bred in the industrial territory of RNO - Alania and, therefore, we studied the content of heavy metals in breast muscle samples of the experimental birds.

The broiler chickens of the 4-experimental group exhibited the most profound detoxification effect which was obtained by supplementing local barley-corn-soybean based feeds with the tested adsorbents, taken in combination. Zinc concentration in the examined muscle samples was 3.48 times lower than in the 1-control group, lead concentration - 3.11 times and cadmium concentration - 3.54 times. It is worth noting that the content of zinc, lead and cadmium in chicken meat of all the experimental groups was below the maximum allowable concentration (MAC). Moreover, the content of the three toxic metals in broiler breast meat samples was lower than in thigh meat samples. In our view, the main reason for that is the increased secretion of exogenous enzymes that was due to the binding of the heavy metals with D-galacturonic acid of citrus pectin which forms strong complexes with the toxic substances, as well as the adsorption of zinc, lead and cadmium ions in the gastrointestinal tract owing to aluminosilicates, yeast culture, gelling agent and marigold extract contained in Toxiban Max.

Conclusion. In the industrial territory of RNO - Alania, the prudent use of the adsorbents such as citrus pectin in the amount of $200 \mathrm{~g} / \mathrm{ton}$ and Toxiban Max in the amount of $1000 \mathrm{~g} / \mathrm{ton}$ admixed to barley-corn-soybean based feeds of local production allows achieving the maximum effect. The broiler chickens of the 4-experimental group were different from the 1-control analogues in weight parameters, slaughter yield and protein qualitative index which increased by $12.9 \%, 0.74 \%$ and $17.8 \%$ respectively. Zinc concentration in the examined muscle samples was 
3.48 times lower than in the 1-control group, lead concentration -3.11 times and cadmium concentration -3.54 times.

\section{References}

1) Baeva A.A., Ktsoeva I.I., Abaev A.V., Vityuk L.A., Kovaleva Yu.I., Payuchek V.G. 2014. Using Sorbents in Feeding for Increasing Environmental and Food Value of Broiler Meat. Scientific Journal of KubSAU (Polythematic online scientific journal of Kuban State Agrarian University) 101, no. 07: 2510-20.

2) Baeva A.A., Vityuk L.A., Abaeva S.K., Buzoeva L.B., Abaev A.V. 2013. Evaluation of Chicken Broiler's Meat when Disturbing the Nutritive Ecology. Izvestia of Gorky State Agrarian University 50, no. 2: 105-10.

3) Daukaev R.A., Suleymanov R.A. 2009. Integrated Evaluation of Heavy Metal Content in Environment Objects of an Industrial City. Sanitary Doctor, no. 3: 34-35.

4) Fyodorov M.V., Kuzmin E.A. 2013. Agriculture and Economic Security of Russia: Retrospective Research. Journal of International Scientific Researches 5, no. 1-2: 42-45.

5) Kokaeva M.G. 2008. Improving the Nutritional Value of Broiler Meat. Paper presented at the $12^{\text {th }}$ All-Russia scientific-practical conference "Agribusiness Industry and Topical Problems of Regions' Economy", in Maikop, Russia.

6) Kuzmin E.A. 2015. Food Security Modelling. Biosciences Biotechnology Research Asia, vol. 12 (Spl. Edn. 2): 773-81.

7) Kuzmin E.A. 2016. Sustainable Food Security: Floating Balance of Markets. International Journal of Economics and Financial Issues 6, no. 1: 37-44.

8) Lopatov S.M. Recommendations on Feeding Poultry by All-Russian Scientific-Research and Technology Institute of Poultry Industry (ARSRTIPI) of the Russian Academy of Agricultural Sciences. ARSRTIPI Publishing, 1999.

9) Senchenko, B.S. Guidelines for veterinary and sanitary examination of animal and vegetable products. Krasnodar. - 1999 .-- S. 478-479.

10) Temiraev R.B., Kokaeva F.F., Tedtova V.V., Baeva A.A., Khadikova M.A., Abaev A.V. 2012. Method for Enhancing the Dietary Qualities of Meat and Increasing Metabolism in Broiler Chickens in the Zone with Serious Anthropogenic Contamination RNO - Alania. Izvestia of Gorky State Agrarian University 49, no. 4: $130-33$.

11) Tletseruk I.R., Temiraev K.B., Tukkaev O.V., Abaev A.V. 2013. Method for Improving Environmental Quality of Poultry Food. New Technologies, no. 3: 128-34. 